\title{
Ana Enriqueta Terán: poetisa de la lengua'
}

\author{
LUIS ALBERTO ANGULO \\ Poeta \\ Venezuela \\ luisalbertoangulorivasunica@yahoo.com
}

(Recibido 24-O6-20I4; aceptado 24-06-2014)

Este año ha sido esencial en la vida de la escritora Ana Enriqueta Terán, tres libros estupendos suyos han sido publicados en los primeros seis meses. Uno de sonetos con dibujos de ella misma (Otros sonetos de todos mis tiempos. Casa Nacional de las Letras Andrés Bello, Caracas), una novela (Apuntes y congojas de una decadencia narrada en tres muertes. Fundación Editorial El Perro y la Rana, Caracas), y a finales del mes de junio - en el marco del XI Festival Mundial de Poesía de Venezuela -, la prestigiosa Biblioteca Ayacucho ha presentado con el No $25^{2}$ de su Colección Clásica a Piedra de habla, antología poética con prólogo de Patricia Guzmán titulado Ana Enriqueta Terán Voz relampagueante de misterio y belleza, amén de la profusa cronología y concienzuda compilación de las fuentes bibliográficas. También este año, el Museo de Arte Valencia conjuntamente con la Red de Escritores de Venezuela y de un grupo de amigos de la poetisa constituidos como comité preparatorio para la celebración del centenario de la escritora, le rindió un cálido homenaje el domingo 4 de mayo, aniversario noventa y seis (96) de su nacimiento en Valera, estado Trujillo, de la ahora República Bolivariana de Venezuela. Este 20I4 es entonces un ítem imprescindible tanto en la cronología como en la bibliografía de una de las voces mayores de la lengua hispana.

Nacida en I9I8 y habiendo publicado Alnorte de la sangre su primer libro en I945, Terán es parte de la generación que realiza su obra fundamental en la segunda mitad del siglo XX en lo que constituye el período más fértil, aunque bastante desconocido internacionalmente de lo que hasta ahora conforma la gran poesía escrita en Venezuela. Tanto este libro, como uno anterior que sólo publicó muchos años después Décimas andinas (1938), fundan su tendencia al cultivo de las formas clásicas de la versificación castellana, que en diferentes etapas ha manejado a profundidad, resaltando siempre la belleza y eficacia del idioma.

\footnotetext{
I Para citar este artículo: Angulo, Luis Alberto (20I4). Ana Enriqueta Terán: poetisa de la lengua. Alabe 9 [www.revistaalabe.com]
} 
Prolífica y comedida al mismo tiempo, su labor creativa mantiene una tensión por la palabra que la ha llevado al cultivo del verso blanco y de la prosa poética, sin abandonar nunca las formas tradicionales a las que ha aportado su contribución en un hacer que la establece como una verdadera clásica de nuestro tiempo. Asumiendo la herencia lírica española, Garcilaso de la Vega, Jorge Manrique, Luis de Góngora, Teresa y Juan de la Cruz (“Los más poetas de todos los santos y los más santos de todos los poetas”), andan todos de su mano compartiendo, junto a la mexicana Sor Juana Inés de la Cruz y con parte de la tradición viva de las llamadas "grandes poetisas del sur" del continente americano a

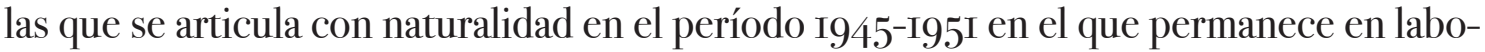
res diplomáticas en Argentina y Uruguay. Por cierto, ella expresa especial reminiscencia por Juana de Ibarbourou quien le prologa Verdor secreto ('49), Juvenal Ortiz Saralegui prologuista de Presencia terrena, así como por otros dos creadores inolvidables de su universo, el chileno Antonio Undurraga y el español Rafael Alberti, exiliado político en Buenos Aires.

Ana Enriqueta Terán es exactamente contemporánea de poetas latinoamericanos como el ecuatoriano César Dávila Andrade, el mexicano Alí Chumaceiro, y el argentino Alberto Girri, nacidos como ella en I9I8. Es coetánea en sentido amplio de muchos otros más de ese continente espiritual en construcción al que también ha aspirado bajo el signo de la Unasur. No obstante, el punto de encuentro con los poetas de su generación no es evidente, al menos que se señale la pluralidad como un elemento unificador de sus poéticas. De todo ese universo de esenciales creadores - y así ha sido sugerido según recuerdo -, es con el más caribeño de todos, el poeta cubano José Lezama Lima, con quien comparte ese sentido arquitectónico del algunas veces llamado el barroco americano en nuestras literaturas. Una visión que en AET surge de la contemplación de la grandiosidad del paisaje del sur y la sonoridad misma de la lengua de sus hablantes, y tal vez tenga que ver también - para ratificar su vinculación a la poética de Lezama Lima -, con la infancia de AET en Puerto Cabello, paisaje de alguna forma similar al de La Habana. Quizás el contraste del mundo andino de donde viene Terán con la espacialidad que le ofrece su mirada al Caribe, determinó también lo que luego cobra sentido en su discurso poético de expresión latinoamericanista. Seis textos en Otros sonetos de todos mis tiempos dedicados al felino José Cemí de su hija Rosa Francisca, son reveladores de la aceptación con esa analogía que ella ha expresado sentirse orgullosa se indique. "En el piso del alma quedó huella / de suavidad, José Cemí y espero / en el piso del alma hacerte espacio / / para tu deambular dulce y severo. / Silencio tú donde silencio sella / gota de miel y acontecer despacio".

En todo caso, no es ocioso afirmar que el talento verbal de Ana Enriqueta Terán ha sido prodigioso en todas sus etapas, desde sus inicios en plena adolescencia, hasta su solitario texto narrativo escrito después de los ochenta y editado este año. Es comprensible hasta cierto punto entonces, que algún abordaje crítico la considere como ave raris en la expresión literaria de su país, pero igualmente, así se pudiera indicar, en el panorama de la poesía latinoamericana. La genialidad lingüística que la ha acompañado siempre, se 
evidencia en sus primeros libros: Al norte de la sangre (I946) y Verdor secreto (I949), e incluso en las Décimas andinas, escritas en I938 y publicadas mucho tiempo después. Empero, la eclosión y madurez poética de Ana Enriqueta Terán se produce a mi modo de ver con Presencia terrena (i949) que la convierte en poeta de la lengua (o poetisa como ella prefiere asumirse desde el fértil castellano), de dimensión clásica con que es percibida por sus coetáneos. Sonetos como "A un caballo blanco" de factura perfecta, u "Oda VI" y "Oda", la erigen junto a nuestras voces mayores.

Es a partir de ese libro que ella comienza un proceso escritural y de publicación de mucha contención, una verdadera lucha interior entre las polaridades en que se debate su creación desbordante, impelida, posiblemente, por el alto nivel de conciencia que este le genera. Cinco años más tarde publica a su regreso a Valencia Testimonio (I954), por solicitud de su amigo el poeta Felipe Herrera Vial director fundador de Cuadernos Cabriales que se inaugura con esa edición. Es un poema de ciento cuarenta y cuatro versos, escrito cuatro años antes bajo el influjo de su arribo al Nahuel Huapi, Neuquén, gran lago de la Patagonia, que la profusa cronología iniciada por José María Beotegui (esposo de AET) y ampliada en Piedra de habla, describe "a lo largo de una sola noche y como raptada".

De bosque a bosque, el próximo libro lo publica en 1970, veintiún años después de Presencia terrena (1949). Poemas cardinales de este título son "Soneto del deseo más alto" y "Soneto intuitivo", que junto al ya referido "A un caballo blanco", se plantan en la cúspide de los grandes sonetos de todos los tiempos. No menos capital por otras razones es "A un vendedor de ostras", cuyo verso final de la primera y segunda estrofa al repetirse, queda sonando de manera perenne en el lector avisado: "y con la imperfección de la belleza”. Ella no dejó de escribir nunca en ese largo espacio temporal de inmensa vitalidad. En París, ciudad donde reside durante el año I953, había iniciado el poemario Música con pie de salmo, su primera obra en "verso libre” que dará a conocer en I985, cuando ya había publicado el Libro de los oficios (i975) que a su vez son poemas escritos en I967, en donde bajo el título premonitorio que reunirá sus textos 47 años más tarde "La poetisa cumple medida y riesgo de la piedra de habla. / Se comporta como a través de otras edades de otros litigios. / Ausculta el día y solo descubre la noche en el plumaje del otoño. / Irrumpe en la sala de las congregaciones vestida del más simple acto. / Se arrodilla con sus riquezas en la madriguera de la iguana”.

Luego de estos magníficos libros, Ana Enriqueta Terán asume el compromiso de compilar en Casa de hablas (I99I) toda su obra publicada o inédita hasta ese momento. La magnitud que esto representa al reunir en un solitario tomo todos sus libros, ofreciendo allí una cantidad increíble de estupendo material inédito, hace que Casa de hablas se perciba como una gran antología, lo que por su calidad en realidad es. Monte Ávila Editores Latinoamericana habrá de reeditarla, considerando, probablemente, la totalidad de la obra posterior reunida en Albatros (1992), Construcciones sobre basamento de niebla (2006), Autobiografía en tercetos trabados con apoyos y descansos en don Luis de Góngora (2007), y de Otros sonetos de todos mis tiempos (2014). 
La posibilidad de edición de la obra poética integral de Ana Enriqueta Terán habrá de tomar en cuenta alguna vez, incluso, y ello no es un capricho totalizante, a sus Apuntes y congojas de una decadencia narrada en tres muertes, la novela que ha publicado este año que permite realizar una enriquecida lectura. La propuesta que se desprende de esta expresión, la emparenta con la poética del decir puro, sin renegar de la fuerza gongorina que ha sostenido siempre el sentido de la hermosa y firme palabra de quien es en este momento, hay que reiterarlo, es una de las voces mayores de nuestra lengua.

A doña Ana Enriqueta Terán le fue concedido el Premio Nacional de Literatura de su país mucho después de los setenta años y cuando ya la Universidad de Carabobo le había conferido un doctorado honorífico. El hecho de que fuera tradicionalmente postergada a ese galardón tan merecido, se convirtió en un tema periodístico en Venezuela. En una de esas ocasiones en que había sido preterida, alguien de la prensa escrita inquirió su parecer y ella respondió como quien le habla a la eternidad: "Mi pelea es con el ángel”. No obstante, ¿habrá que esperar el centenario de su nacimiento para que reciba en vida un reconocimiento universal?

Bárbula, 24 - 06 - 20I4.

Aniversario de la Batalla de Carabobo y día de San Juan B. 


\section{Poemas de Ana Enriqueta Terán}

Selección de Luis Alberto Angulo*

\section{ODA VI}

La soledad me envía mensajeros de llanto,

los recibo en los mares nocturnos de mi pecho,

en los hombros del agua que crece hasta mis sienes

y en el oscuro limo de la entraña y del beso.

Camino con las olas y con el árbol dado

a la corteza muda que me hiere y me enciende,

camino con la tierra y un entreabierto goce

me lastima y conduce más desnuda la frente.

Alguien me dijo algo de bestias taciturnas,

de mares y tinieblas que azotaban mi rostro,

escuchaba su voz y buscaba su cuerpo

por altos corredores sin llegar a su lodo.

Existo. Me detengo para escuchar mi muerte

que viene por mi sangre como un hondo latido

mi muerte tiene en mí, cantos de mansedumbre

y secretas constancias del amor y el olvido.

Existo por mi muerte, para mi muerte y amo

libremente mi vida, libremente mi muerte

con su silencio en alas de ardientes mariposas

escucho, me detengo en sus frágiles sienes. 
Y recuerdo la mar, siempre la mar echada a la orilla de un árbol limpio como la vida; el sueño con mesetas minerales y espumas de soledad, la mar a ciegas por la orilla.

Puedo decir: "las rosas" y decir "estas rosas son de umbrales nocturnos de secretas fogatas abiertos en los llanos, o son rosas marinas de sentidos azules, sin rumbos ni distancias”. Yo escuchaba las rosas porque si desde el sueño descontando matices y savias verdaderas, el olvido me daba con su primer recuerdo, memorias en la gracia de la sal y la tierra.

Que la ciudad entera viene de lo salobre lo digo, por mis sienes y por mi voz primera.

(Alnorte de la sangre. Odas. 1946)

\section{A UN CABALLO BLANCO}

Qué fragor en las crines, qué lamento de cuello hasta los belfos conquistado, resbaladas llanuras al costado: ¡caballo blanco por mi solo intento!

Copian sus ojos el paisaje lento y un árbol en el fondo gime anclado, los tintes del azul y del morado, trepan sus ancas, siguen en el viento. 
Huye de mí, se pierde en la verdura de las yerbas crecidas, adelanta su pecho hasta el poniente y la espesura,

huye de mí como una racha oscura

y blanco desde el pecho a la garganta

en el fondo de mí canta su albura.

(Presencia terrena, I949)

\section{SONETO DEL DESEO MÁS ALTO}

Necesito un anillo delirante

para la oculta sombra de mi mano, un archivo de mar para el verano y documentos de agua suplicante.

Para mi mano un riguroso guante de piel de tiempo y pensamiento vano y la mesa de juego donde gano contra la muerte mi color menguante.

Una sortija de algas con países y lenguas diferentes, con nocturnos bisontes y cuadernos vegetales;

para mi mano los rebaños grises, las edades de tactos taciturnos y el pulso de los secos minerales. 


\section{ZAZÁRIDA}

Zazárida es una ciudad frecuentada por el llanto.

Ciudad con estatura y manejos de sueño.

Ciudad como águila, un instante, amortajada en lo profundo.

Ciudad con perros agudos meando el aire y trágicas pertenencias:

la historia como sartas de coral sobre el balanceo de los viajes.

Un poco también humildad, párpados de nación muy poco amada.

Y también nuevo deleite para las grandes señoras negras,

especialmente para la vieja dama negra de mi amistad,

que pespuntea colinas con su báculo de regio araguaney,

escenificando viejos tratos, restituciones, lóbregos sucesos.

Zazárida, ciudad de habla mayor difícilmente nuestra

en su oficio de FUTURO.

(Libro de los oficios, 1975)

\section{QUEJA Y NOSTALGIA DEL PROPIO CANTO}

El mar respira hondo en la casa abandonada.

Nuestra infancia alma mía

como el aroma

de una provincia desnuda.

Tan lunes y mi perro al relieve frente a tinajas lúgubres.

¡Oh! la solemne despedida el confuso adiós de lo que permanece.

Sin embargo

echo de menos otra nave

otros mares con pestañas de música.

El mar sobre esta playa abre y cierra sus abanicos eternos.

Él hunde su constancia en los muslos taciturnos.

Descubre en las axilas de la patria 
algún olor de ciudad entrañable.

Deja a otros la queja múltiple: el águila ese hecho celeste

para humillación del torso desnudo. El mar respira hondo en la casa abandonada. Crea sin regocijo nuevas formas de silencio para el espectro nupcial que fluye y refluye en el mármol sin belleza. El mar y yo alma mía desconocemos este canto esta bandera inobjetable en su ritmo

alabada en su inmóvil libertad que a su vez desconoce la involuntaria reverencia del jorobado al can del prostíbulo. Más aún: vaciado en yeso los ojos de la prostituta ciega.

Y la paralizante lucidez de esta mar

de este fuego siniestro

en la palma de la mano.

(Música con pie de salmo, 1985)

\section{PERSONAS Y ROPAS CLARAS}

Se distingue entre todas. Casa del alma.

Casa bermeja revolando en lo oscuro, lanzando retos sopesando odios: la rabia grande y burladeros de la dicha.

Casa de pasos resguardada por alientos del Sur. Ama el Sur.

Escoge trapos de lustre para inicio y doblaje de nuevos usos, nuevas hablas acodadas en ventanales de bruma. Casa de hablas. Casa con latigazos de monte en piso y risas como puntos de eternidad entre personas y ropas claras. Casa y plantaje de dureza. Último modo para lo permanente y exacto. 


\section{SOMOS PRIMOS}

-"Somos primos"-, nos dice el bello loco

emergiendo de sus catedrales azules

de antiguos diálogos como señales en la niebla.

¡Ay! El desperezo de la noche en las galleras abandonadas.

El sombrío galope de los vencidos caballeros.

La confidencia de las ancianas vírgenes:

-“Nos entregaron polainas y espuelas de oro”.

(Música con pie de salmo, I985)

\section{MODO DE IRSE}

Interrumpa la flor, deje su luz, (la de la flor), en lo afilado del verbo;

no sucumba a las nuevas dichas, abrace tan solo el árbol.

Aprenda del follaje modo de irse, seguir ondas, escalones, pisos de aves.

Instruya sus labios con frutas oscuras; úntelos de tinieblas.

Escoja de cada nube lo que perece y se ciñe al viento y cubre días, pasos, sonoridades anteriores.

(Libro de Jajó, 1980- ${ }^{\circ} 87$ ) 


\section{ELNOMBRE}

Como quien escribe una oración y pide en la oración mucha humildad y un extenso aliento para resistir el brillo y cercanía de la PALABRA.

Es mi oficio y la frase resulta de arena negra con pespuntes de oro. Y pide en la oración mucha obediencia y la aceptación del nombre.

No la firma, sino el nombre completo en los calveros de poema:

\section{ANA TERÁN.}

\section{ANA TERÁN MADRID.}

\section{ANA ENRIQUETA TERÁN.}

Me gusta este nombre. Esta soledad y raro artificio que se desprende de mí hacia la profecía. Que es yo misma recorriendo las islas, el espacio comprendido entre mi desamparo y las escamas, anillos y mordeduras del CLIMA.

(Libro de los oficios, I975)

\section{SE ME OLVIDÓ LA RISA, CLARA RISA}

Se me olvidó la risa, clara risa

para informar banderas contra el viento

o suspender las aves, dulce intento

de volver seda lo anterior a brisa.

De volver seda pálida sonrisa acosada de mitos y momento de traspasar el singular lamento queja inútil, sagrada, con la prisa 
de quien ha de partir y le da paso

a la vieja querella imaginada

más que cierta en el ámbito preciso

de no querer ya nada, nada nada...

o solamente recordar un trazo

de luna en la tiniebla sosegada

de este octubre en la casa y en el piso.

Casa de Hablas, 8 o 9 de octubre de 2013

(Otros sonetos de todos mis tiempos, 20I4)

\section{ENSIMISMADA LUCIDEZ}

Borra símbolos para hallar centro de luz en presencia fija.

Intuye presencia y nunca tanto caracol asfixiado en espirales de nada,

ideando modos, gesto o palabra, para ver, solamente ver...

Nunca tanto implorar por tactos que tropiecen en algo,

alguna señal de textura ardida

para ver, solamente ver.

(Construcciones sobre basamentos de niebla, 2006) 


\section{SONETO CINCUENTA}

Definitivamente estoy despierta

en un claro de patria donde abrazo

mis dos casas terribles y rechazo

planchada luz de página desierta.

Digo y lo dicho me asegura el paso que atraviesa la rosa y la convierta de creatura perenne y entreabierta en ave fija de enlutado trazo;

digo como una planta que obedece en sueños y enseguida restablece bestia tupida, sorda, desligada,

inútilmente libre, enmarañada.

Sobre lo escrito, girasol o nada.

Sin embargo, lo escrito permanece.

(Autobiografía en tercetos trabados con apoyos y descansos en don Luis de Góngora, 2007) 


\section{LA POETISA CUENTA HASTA CIEN Y SE RETIRA}

La poetisa recoge hierba de entretiempo,

pan viejo, ceniza especial de cuchillo;

hierbas para el suceso y las iniciaciones.

Le gusta acaso la herencia que asumen los fuertes,

el grupo estudioso, libre de mano y cerrado de corazón.

Quién, él o ella, juramentados, destinados al futuro.

Hijos de perra clamando tan dulcemente por el verbo,

implorando cómo llegar a la santa a su lenguaje de neblina.

Anoche hubo piedras en la espalda de una nación,

carbón mucho frotado en mejillas de aldea lejana.

Pero después dieron las gracias, juntaron, desmintieron,

retiraron junio y julio para el hambre. Que hubiese hambre.

La niña buena cuenta hasta cien y se retira.

La niña mala cuenta hasta cien y se retira.

La poetisa cuenta hasta cien y se retira.

(Libro de los oficios, 1975) 


\section{Fuente de la selección de poemas:}

- Terán, A. E. Piedra de habla. Biblioteca Ayacucho. Colección Clásica. № 252. Caracas, 20I4. P. 364

- Terán, A. E. Otros sonetos de todos mis tiempos. Casa Nacional Andrés Bello. Caracas. Caracas 20I4. P. I66

- Angulo, L. A. Rostro y poesía, poetas de la Universidad de Carabobo. Oficina del Cronista de la UC. Valencia, Venezuela, r994. P. 280

- Angulo, L.A. Revista Nacional de Cultura. № 3I3. 2000.

*ANA ENRIQUETA TERÁN. Poeta venezolana (Valera, estado Trujillo, i9r8). Premio Nacional de Literatura de Venezuela (I989-I99o). Doctorado Honoris Causa de la Universidad de Carabobo, Valencia (I989). Sus ediciones más recientes son: Piedra de habla (Biblioteca Ayacucho. Colección Clásica. № 252. Caracas, 20I4), Otros sonetos de todos mis tiempos. Casa Nacional Andrés Bello. Caracas. Caracas 2014), Autobiografía en tercetos trabados con apoyos y descansos en don Luis de Góngora (Fundación Editorial El perro y la rana, Caracas, 2007), Antología poética (Fundación Editorial El perro y la rana, Biblioteca Popular para loa Consejos Comunales, Caracas, 2007), Construcciones sobre basamento de niebla (Monte Ávila Editores Latinoamericana, Caracas 2006), Antología poética (Monte Ávila Editores Latinoamericana, Biblioteca Básica de Autores Venezolanos, Caracas, 2005), Antología Mínima (Fondo Editorial Arturo Cardoso, Trujillo, 2003), Albatros (Universidad de los Andes, Mérida r992), Casa de hablas: obra poética I946-I989 (Monte Ávila Editores Latinoamericana, Caracas, I99I). Se deben reseñar, igualmente a: The poetess counts to 100 and bows out. Marcel Smith; trad. Princeton, N.J. Princeton University Press, 2003. II9 p. Bilingual edition, así como a William Rowe "Ana Enriqueta Terán: In the Midst of Things" en Poets of Contemporary Latin America: History and the Inner Life. Oxford University Press, Oxford Hispanic Studies, 2000, 370 p. 